\title{
Identificación de microbiota bucal en caninos en estado de abandono
}

\author{
Identification of Bucal Microbiota in Canines in State of Abandonment \\ Lucia Constanza Corrales MScํㅜ, Diana Marcela Antolinez Romero², Johanna Azucena Bohórquez Macías², \\ Aura Marcela Corredor Vargas ${ }^{2}$
}

\section{Resumen}

Objetivo. Describir la microbiota que se encuentra en la cavidad bucal de caninos en condición de abandono de la Fundación Razas Únicas en el municipio de Chía Cundinamarca. Métodos. Para el estudio se tomaron 29 muestras orales con escobillón a 23 caninos de la Fundación Razas Únicas del municipio de Chía - Cundinamarca. 23 muestras se recolectaron para identificación de bacterias aerobias y anaerobias facultativas, las cuales se transportaron en medio líquido tripticasa soya y 6 muestras para recuperación de bacterias anaerobias estrictas transportadas en medio VMGA-III. El aislamiento de los microorganismos se realizó en medios selectivos y la identificación con el sistema BD BBL ${ }^{\mathrm{TM}} \mathrm{Crystal}^{\mathrm{TM}}$. Resultados. De las 29 muestras analizadas se aislaron 59 bacterias, entre ellas 15 géneros y 15 especies diferentes como; Escherichia coli, Proteus mirabilis, Citrobacter freundii, Enterobacter sakazakii, Enterobacter cloacae, Enterococcus durans, Enterococcus faecalis, Eikenella corrodens, Porphyromonas endodontalis, Fusobacterium spp y Capnocytophaga spp. De acuerdo con la revisión de la literatura, las bacterias anaerobias encontradas están principalmente relacionadas con enfermedad periodontal y las enterobacterias con contaminación oro-fecal.

Palabras claves: Microbiota, cavidad bucal, anaerobios estrictos, aerobios, anaerobios facultativos, enfermedad periodontal, mordeduras.

\footnotetext{
1 Docente investigadora. Universidad Colegio Mayor de Cundinamarca. Bogotá, Colombia.

2 Bacteriólogas y Laboratoristas Clínico, Facultad de Ciencias de la Salud. Universidad Colegio Mayor de Cundinamarca. Bogotá, Colombia.

Correspondencia: lcorrales@unicolmayor.edu.com 


\section{Abstract}

Objective. To describe the microbiota found in the oral cavity of canines in condition of abandonment of the Razas Únicas Foundation in the municipality of Chía - Cundinamarca. Methods. For the study, 29 oral samples were taken with a brush from 23 canines from the Razas Únicas Foundation of the municipality of Chía - Cundinamarca. 23 samples were collected for identification of facultative aerobic and anaerobic bacteria, which were transported in soybean tripticase liquid medium and 6 samples for recovery of strict anaerobic bacteria transported in VMGA-III medium. The isolation of the microorganisms was carried out in selective media and identification with the BD BBL ${ }^{\mathrm{TM}}$ Crystal ${ }^{\mathrm{TM}}$ system. Results. From the 29 samples analyzed, 59 bacteria were isolated, including 15 genera and 15 different species such as Escherichia coli, Proteus mirabilis, Citrobacter freundii, Enterobacter sakazakii, Enterobacter cloacae, Enterococcus durans, Enterococcus faecalis, Eikenella corrodens, Porphyromonas endodontalis, Fusobacterium spp and Capnocytophaga spp. According to the review of the literature, the anaerobic bacteria found are mainly related to periodontal disease and the enterobacteria with oral-fecal contamination.

Keywords: Microbiota, Oral Cavity, Strict Anaerobes, Aerobes, Facultative Anaerobes, Periodontal Disease, Bites.

\section{Introducción}

En los humanos se han realizado diversos y múltiples estudios sobre la microbiota de la cavidad oral y es tema que continúa en estudio dadas las nuevas técnicas de identificación con que se cuenta, no tanto así a nivel de las especies animales, asunto por lo demás importante por ser uno de los microsistemas que más densidad bacteriana tiene en el organismo y Colombia no es la excepción.

La cavidad oral, por su conformación anatómica y diversidad de tejidos que se encuentran allí, facilita la coexistencia de variados ecosistemas microbianos, con sus particularidades metabólicas y nutriciona- les, que generan beneficio mutuo y conlleva a establecerse un ecoequilibrio que favorece el desarrollo de cada uno de ellos.

En el momento del nacimiento de los caninos, la mucosa de la boca es a menudo estéril, la primera contaminación se da durante el paso a través del conducto vaginal De 4 a 12 horas después del nacimiento se establece la flora residente y los siguientes microorganismos que colonizan esta mucosa son los que se encuentran en el medio ambiente en estado libre (1). Durante los primeros meses de vida del cachorro se añaden Staphylococcus spp aerobios, diplococos Gram negativos, Difteroides y, ocasionalmente, Lactobacilos. Cuando inicia la dentición aparecen nuevos hábitats para 
la colonización como el esmalte dental y el surco gingival, permitiendo la aparición de nuevos microorganismos como espiroquetas anaerobias principalmente del género Treponema, Bacteroides spp, Fusobacterium spp, Actinomyces spp, Veillonella spp, especies de Rothia y Capnocytophaga; así como algunos vibriones anaerobios. Además, se presenta con mayor relevancia en la placa supragingival bacterias como Bergeyella zoohelcum, Neisseria spp, y Moraxella spp. (2). Cuando se produce la erupción de los dientes permanentes en el periodo de recambio se acompańa de fenómenos inflamatorios, permitiendo favorecer la colonización de bacterias patógenas. Ya en los caninos adultos se encuentran especies de Actinomyces spp en amígdalas y encías (3).

La microbiota natural de la cavidad oral de perros depende de varios factores como la edad, la alimentación, cambios ambientales, estado inmunológico y la salud de los dientes y encías, y en general, del estado de salud del huésped (4). Las bacterias encontradas en la cavidad oral sana están representadas en su mayoría por especies anaerobias facultativas, mientras que la microbiota subgingival de caninos con enfermedad periodontal es de predominio anaerobio estricto. Entre las bacterias predominantes de la cavidad oral sana se encuentran Pasteurella multocida, Streptococcus spp, Staphylococus spp, especies de enterobacterias (Proteus $s p$ ) y otros como Corynebacterium $s p p$, Eikenella corrodens, Clostridium spp, Peptostreptococcus spp y Propionibacterium spp. $(5,6)$.
En cuanto a los hábitos, cabe destacar el tipo de alimentación. A este respecto se observa que una dieta blanda generalmente favorece la acumulación de residuos de comida dentro y en los alrededores de los dientes. Otros hábitos son los comportamentales como masticar huesos, piedras o madera ya que estos pueden causar daño en la gingiva y favorecer el desarrollo de infección (7).

Sin embargo, aunque hay bacterias que no generan ningún tipo de compromiso en la boca del animal, hay otras bacterias que son patógenas y pueden llegar a desencadenar procesos inflamatorios o lesiones orales que a su vez pueden ser causantes del inicio y desarrollo de enfermedad periodontal, lo cual depende principalmente del estado de salud en que se encuentra el animal y de sus hábitos.

Al respecto países como Inglaterra, Chile, Brasil y Argentina reportan estudios descriptivos en los cuales clasifican los microorganismos dependiendo de la o las patologías específicas que estén cursando, principalmente periodontitis y signos o lesiones orales. La diversidad de bacterias encontradas también depende de la localización anatómica de la boca y del tipo de la muestra. A este respecto se encuentra que en la placa madura se reduce la concentración de oxígeno del margen y surco gingival favoreciendo el crecimiento de microorganismos anaerobios facultativos y anaerobios estrictos como Actinomyces spp y Streptococcus spp. Por otro lado, la saliva es 
la muestra en donde se encuentran la mayoría de microorganismos, probablemente porque el $\mathrm{pH}$ alcalino facilita su proliferación; predominando los coliformes, bacterias cuya presencia se relaciona posiblemente con conductas de los caninos como el lamido en su acicalamiento y la ingesta de heces. En los caninos con periodontitis predominan en la placa supra y subgingival microorganismos anaeróbicos como Bacteroides spp, Porphyromonas pigmentadas y no pigmentadas, Prevotella spp y Fusobacterium spp. (8).

En el surco gingival se encuentran bacterias aerobias y anaerobias. En los dientes se presentan superficies de adherencia que no tienden a renovarse periódicamente, como los epitelios. En su composición predominan diferentes especies de Streptococcus a hemolíticos, como Streptococcus mutans y Streptococcus sanguis, a nivel de la placa dentaria. Streptococcus mitis se encuentra adherido tanto a los dientes como a las mucosas y Streptococcus salivarius predomina en la mucosa lingual.

A nivel de la placa se encuentran gérmenes anaerobios Gram positivos como $A c$ tinomyces spp, Bifidobacterium y algunas especies de Lactobacillus, en menor cantidad. La mayoría de los Gram negativos son anaerobios como Bacteroides del grupo melaninogenicus y especies del género Fusobacterium spp, Eikenella corrodens, Pasteurella spp, Porphyromonas spp y Prevotella $s p p$, pero también se encuentran aerobios como Neisseria spp.
Dentro de las bacterias fastidiosas se encuentra Capnocytophaga canimorsus siendo este un bacilo Gram negativo (9). Además, pueden encontrarse espiroquetas del género Treponema dependiendo de la edad del canino. Dentro de los cocos Gram positivos anaerobios se encuentran los géneros $P e p$ tococcus, Peptostreptococcus y Ruminococcus entre otros. Pueden además aislarse especies de Mycoplasma y levaduras del género Cándida principalmente C. albicans. (10).

El papel que cumplen las bacterias en la cavidad bucal es variada. Por ejemplo, los biofilms que colonizan la cavidad oral son uno de los más complejos que existen en la naturaleza. Esta complejidad se debe en gran medida a la composición de las distintas superficies en la cavidad oral de caninos, que determinan la existencia de cuatro nichos orales diferentes que son: mucosa masticatoria, mucosa dorso lingual, saliva y superficies duras (superficies dentales y materiales de restauración). Estos biofilms tienden a incrementarse con la edad alcanzando un $80 \%$ en perros por encima de los cinco años de edad (11).

La microbiota bucal parece desarrollar diferentes funciones beneficiosas para los caninos, entre las cuales se destaca la prevención de la colonización de las superficies bucales por patógenos potenciales. La cavidad oral está permanentemente colonizada por una microbiota normal residente que se organiza en ecosistemas donde se encuentran especies que, en ocasiones, pueden comportarse como patógenas, dependiendo del 
estado inmunológico del canino. (12). Los microorganismos pertenecientes a la microbiota bucal normal contribuyen al desarrollo de la respuesta inmunológica; además, ayudan a evitar la colonización de la piel o las mucosas por bacterias que pueden ser patógenas. Los gérmenes para iniciar la infección deben, en general, comenzar por colonizar los epitelios, en donde seguramente compiten con los integrantes de la microbiota por factores tales como receptores celulares y nutrientes.

De esta manera, la microbiota normal juega un papel importante en la producción de efectos directos como la producción de bacteriocinas, metabolitos tóxicos, reducción del potencial redox, consumo de nutrientes esenciales y competencia por receptores. Dentro de los efectos indirectos se encuentra el aumento de la producción de anticuerpos, estímulo de la fagocitosis y aumento de la producción de interferón (13).

La colonización de los microorganismos se da mediante la penetración a los tejidos a través de dos vías: la dentaria y la periodontal; y una vez ingresan, avanzan hasta donde las defensas del cuerpo se lo permitan. Dicho avance se da a través de los tejidos de la región buco-maxilo-facial. Las primeras bacterias en penetrar el tejido son los Streptococcus del grupo viridans, por ser facultativas. La entrada de estas bacterias causará la siguiente secuencia de cambios: consumo total del oxígeno existente, generando un ambiente de anaerobiosis, que facilita el ingreso de bacterias anaeróbicas, lisis tisular y formación de abscesos. Una vez trascurrida esta primera colonización de microorganismos patógenos, el canino se hace más susceptible a la incorporación de cualquier microorganismo que sobrepase las barreras de defensa exacerbadas (14).

En un estudio realizado en España por Cabrera y cols. (11), se encontró un reporte de 10 caninos de la raza Beagle con enfermedad periodontal inducida en hembras y machos, con una edad promedio de 1 a 3 ańos y un peso vivo entre $9 \mathrm{Kg}$ y $11 \mathrm{~kg}$, potencialmente inmunosuprimidos. Este estudio se realizó a partir de la placa supragingival en donde se identificaron especies como Proteus mirabilis, Neisseria spp, Pseudomonas spp, Escherichia coli, Staphylococcus epidermidis, Staphylococcus coagulasa negativa, Streptococcus a hemolítico, Streptococcus $\beta$ hemolítico, Streptococcus pneumoniae, Lactobacillus spp, Nocardia spp, Actinomyces spp, Corynebacterium spp, Micrococcus spp, Microbacterium spp., resaltando que Neisseria spp y Streptococcus a hemolítico estuvieron presentes en las 10 muestras. Sin embargo, hay autores que consideran a Neisseria spp como parte de la flora normal de la cavidad oral en el perro.

En Bolivia se han descrito estudios asociados a mordeduras por caninos, en los cuales se clasifican las complicaciones dependiendo del grado de infección, sitio anatómico de la lesión, profundidad, microorganismo que ocasiona la infección y el estado del sistema inmune del humano lesionado. La infección progresa con rapidez y se hace 
evidente en las primeras 8 a 24 horas, concluyendo que las mordeduras por caninos representan un problema de salud pública y que estas mordeduras representan un riesgo de infección para el humano; cuya gravedad está sujeta a las características de la lesión y a su manejo, siendo Staphylococcus aureus y Pasteurella multocida los gérmenes aerobios más frecuentemente aislados en las heridas por mordeduras de caninos $(4,15)$.

Varios informes describen que tanto en el humano como en el perro se presenta el paso de bacterias orales, como Pasteurella multocida y Tannerella forsythia, las cuales han sido vinculadas a infecciones humanas locales y sistémicas (16). Para la identificación de la flora bacteriana en caninos se han utilizado los mismos métodos, tecnologías y descripción que para la identificación de la flora bacteriana en los humanos, por lo que en la actualidad no están estandarizados los criterios específicos para el estudio de la microbiota oral en esta especie animal. Un ejemplo de ello es el caso de Porphyromonas gingivalis, que en caninos presenta características fenotípicas diferentes a las cepas humanas ocasionando dificultades en el momento de su identificación (17).

La identificación de la microbiota bacteriana presente en la cavidad bucal de caninos en condición de abandono de la fundación Razas Únicas ubicada en el municipio de Chía (Cundinamarca - Colombia), permite hacer un acercamiento al tipo de bacterias que se encuentran asociadas a infecciones en la cavidad bucal, así como las infecciones por bacterias que se adquieren en caso de mordeduras, lo cual proporciona información que orientará el tratamiento terapéutico.

El presente estudio se realiza a partir de 29 muestras tomadas aleatoriamente de $23 \mathrm{ca}$ ninos en estado de abandono de la Fundación Razas Únicas, con el fin de identificar las bacterias presentes en la cavidad oral, así como observar el impacto que éstas puedan tener a nivel de la salud del animal y de la salud pública, ya que muchos de los microorganismos presentes en la boca de los animales pueden ser potenciales infectantes a través de mordeduras. En Colombia no se han realizado estudios sobre la identificación de las bacterias de la cavidad bucal en caninos, por lo cual este estudio busca proporcionar información sobre qué tipo de bacterias se pueden encontrar y de esta forma proporcionar herramientas que permitan realizar un mejor manejo a nivel de la salud veterinaria y del humano.

Es necesario aclarar que en esta investigación no se pretende afirmar que los caninos tienen o fueron diagnosticados con enfermedad periodontal por lo que ese tema quedará abierto para otros estudios.

\section{Materiales y métodos}

En el estudio se analizaron las variables de las muestras obtenidas de cada uno de los individuos y se interpretaron los resultados de acuerdo con las bacterias identificadas. 
- Universo: caninos de la Fundación Razas Únicas que se encuentra ubicada en el municipio de Chía - Cundinamarca.

- Población: 180 caninos en condición de abandono

- Muestra: 23 caninos seleccionados aleatoriamente

Se realizó la visita a la Fundación Razas Únicas ubicado en el municipio de Chía-Cundinamarca (Colombia), en donde se encontraron 180 caninos en estado de abandono tanto criollos como de raza, cachorros y adultos, todos bajo las mismas condiciones de manejo, alimentación y de ambiente. De estos se escogieron 23 caninos aleatoriamente en donde se consideró como único criterio de exclusión estar en tratamiento en el momento de la toma de muestra o en lapso no inferior a 30 días.

\section{Recolección de información de cada canino}

La información se recolectó mediante encuesta diligenciada por la persona encarga- da de la fundación, con el fin de identificar y caracterizar los caninos mediante los siguientes datos: nombre, género, edad, tamaño, raza, peso, fecha de ultima desparasitación, vacunación, color y observaciones.

\section{Recolección de la muestra}

La toma de la muestra se realizó mediante hisopado bucal con escobillones estériles, que consistió en frotar con un hisopo la cara interna de la boca, las encías y los dientes de cada uno de los caninos; luego se introdujeron en tubos de vidrio con $3 \mathrm{~mL}$ de medio líquido tripticasa soya para recuperación de aerobios y anaerobios facultativos. Para microorganismos anaerobios estrictos se tomaron 6 muestras aleatorias a de los 23 - 24 (identificadas como muestra 4, muestra 8 , muestra 10 , muestra 14 , muestra 20 , muestra 21) por medio de puntas odontológicas, las cuales se introdujeron en el medio de transporte VMGA-III (Viability Medium Göteborg Anaerobically)

Figura 1. Jein - Pitbull. Toma de muestra a los caninos de la Fundación Razas Únicas de Chía- Cundinamarca.

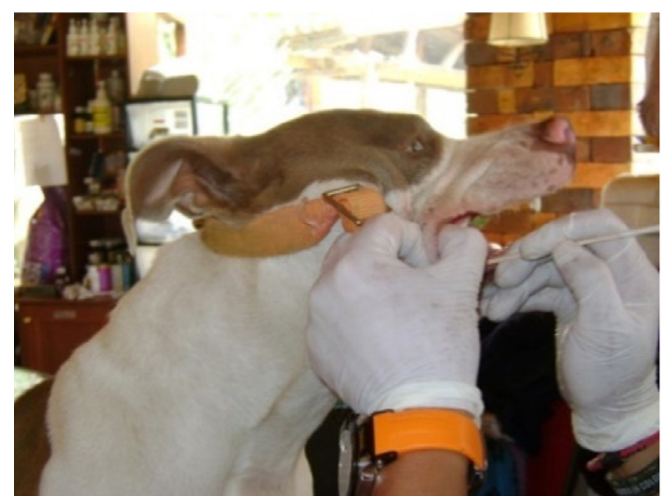

Fuente. Elaboración propia. 
Figura 2. Toma de muestra a los caninos de la Fundación Razas Únicas de Chía- Cundinamarca. Romana - Criolla.



Fuente. Elaboración propia.

\section{Clasificación por edad}

Se utilizó la clasificación descrita por Logan (18) para determinar la existencia de aso- ciación entre ciertos microorganismos con determinados grupos de edades, como se observa en la Tabla 1.

Tabla 1. Clasificación por edad de los caninos.

\begin{tabular}{|l|l|}
\multicolumn{1}{|c|}{ EDAD } & \multicolumn{1}{c|}{ GRUPO } \\
\hline Joven & Hasta 1 año \\
\hline Adulto & Desde 13 meses hasta menores de 7 años \\
\hline Viejo & Mayores de 7 años \\
\hline
\end{tabular}

Fuente. Elaboración propia.

\section{Clasificación por raza (tamaño)}

Se aplicó la clasificación descrita por Logan (18), correspondiente a tres grupos de acuerdo al tamańo relacionado con la raza (peso) del paciente, para determinar la existencia de asociación entre ciertos microorganismos y el tamaño del animal, en términos de raza y peso de éstos, tal como se presenta en la Tabla 2.

Tabla 2. Clasificación por tamaño.

\begin{tabular}{|l|l|}
\multicolumn{1}{|c|}{ PESO (EN KG.) } & \multicolumn{1}{c|}{ TAMANO DE RAZA } \\
\hline Menos de 10 & Pequeña \\
\hline 10 a 25 & Mediana \\
\hline 26 o más & Grande \\
\hline
\end{tabular}

Fuente. Elaboración propia. 


\section{Procesamiento de las muestras}

Las muestras para el aislamiento e identificación de las bacterias aerobias y anaerobias facultativas se procesaron en los laboratorios de la Universidad Colegio Mayor de Cundinamarca. Los tubos con el caldo se incubaron 24 horas a $37^{\circ} \mathrm{C}$, posteriormente se sembraron en agar sangre de cordero al $5 \%$, para el aislamiento de microorganismos aerobios y determinar la capacidad hemolítica de los mismos, agar chocolate para el aislamiento y recuperación de microorganismos de crecimiento exigente, agar MacConkey para la selección de bacilos Gram negativos no exigentes y su diferenciación de acuerdo con la fermentación de lactosa y agar tripticasa soya para la recuperación de cualquier microorganismo presente, ya que favorece el desarrollo y aislamiento de una gran variedad de microorganismos aerobios y anaerobios facultativos. En el protocolo se realizó control de esterilidad, viabilidad y reproducibilidad con cepas Staphylococcus aureus ATCC 25923 y Escherichia coli ATCC 25922, proporcionadas por el Cepario de la Universidad Colegio Mayor de Cundinamarca. La siembra se realizó con asa por la técnica de agotamiento.

Después de 24 horas de incubación a $37^{\circ} \mathrm{C}$, se visualizó el crecimiento y se realizó coloración de Gram para confirmar morfología y afinidad por la tinción. Los controles del Gram se realizaron con las cepas de Staphylococcus aureus ATCC 25923 y Escherichia coli ATCC 25922 suministradas por el
Cepario de la Universidad Colegio Mayor de Cundinamarca.

Una vez realizada la descripción macro y microscópica se realizaron catalasa y oxidasa y la identificación mediante el sistema BD BBL ${ }^{\mathrm{TM}}$ Crystal $^{\mathrm{TM}}$ Gram-Positive ID Kit y el BD BBL ${ }^{\mathrm{TM}}$ Crystal $^{\mathrm{TM}}$ Enteric/Nonfermenter ID Kit.

Las 6 muestras para bacterias anaerobias contenidas en el medio de transporte VMGA-III, se procesaron en la unidad de investigación básica oral (UIBO) de la Universidad el Bosque. De éste se realizaron tres diluciones en el caldo VMGA-I (Viability Medium Göteborg Anaerobically), y se sembraron las diluciones $(-5,-4,-3)$ en agar Brucella suplementado con hemina y vitamina K1 para favorecer el crecimiento de anaerobios exigentes. Se incubó por 8 días en condición de anaerobiosis con el sistema GasPak. Posterior a la incubación se observó la morfología macroscópica de las colonias por medio del estereoscopio, realizando el recuento de unidades formadoras de colonia (UFC). Las colonias sin identificar se sembraron de nuevo en agar Brucella suplementado por 8 días en condición de anaerobiosis, se realizó tinción de Gram para confirmar afinidad por la tinción y su morfología. Luego se realizaron pruebas presuntivas como Indol, oxidasa y ONPG. Luego se procedió a la identificación mediante el uso de la técnica BD BBL-Crystal Identification Systems- Anaerobe ID Kit. 


\section{Resultados}

razas: Basset hound $(\mathrm{n}=1)$, Fox terrier $(\mathrm{n}$ $=1)$, Bull mastiff $(\mathrm{n}=1)$, Pitbull $(\mathrm{n}=3)$, Los caninos estaban siendo alimentados Beagle $(n=4)$, Labrador $(n=2)$, Bull dog con dietas comerciales (concentrados du- $(\mathrm{n}=1)$, Bull terrier $(\mathrm{n}=1)$, y de raza mixta ros). Los caninos tenían una edad entre 6 o criolla $(n=9)$. La raza, la edad y el sexo de meses a 12 años y pertenecían a diferentes cada perro se muestran en la Tabla 3.

Tabla 3. Descripción etnográfica de las muestras.

\begin{tabular}{|c|c|c|c|c|}
\hline MUESTRA & $\begin{array}{c}\text { IDENTIFICACIÓN } \\
\text { CANINO }\end{array}$ & SEXO & EDAD & RAZA \\
\hline 1 & Romana & Hembra & 4 años & Criolla \\
\hline 2 & Moises & Macho & 6 meses & Cruce labrador \\
\hline 3 & Jein & Macho & 5 años & Pitbull \\
\hline 4 & Chia & Hembra & 11 años & Basset hound \\
\hline 5 & Ice & Hembra & 3 años & Criolla \\
\hline 6 & Mila & Hembra & 7 años & Beagle \\
\hline 7 & Lucas & Macho & 3 años & Cruce San Bernardo \\
\hline 8 & Mateo & Macho & 4 años & Fox terrier \\
\hline 9 & Mufasa & Macho & 10 meses & Bull mastiff \\
\hline 10 & Guache & Macho & 11 meses & Pitbull \\
\hline 11 & Tobi & Macho & 2 años & Labrador \\
\hline 12 & Pecas & Macho & 5 ańos & Beagle \\
\hline 13 & Rodrigo & Macho & 1 año & Criollo \\
\hline 14 & Tommy & Macho & 1 año & Pitbull \\
\hline 15 & Laika & Hembra & 4 ańos & Bulldog \\
\hline 16 & Tara & Hembra & 6 años & Beagle \\
\hline 17 & Mono & Macho & 3 años & Criollo \\
\hline 18 & Zeus & Macho & 7 años & Beagle \\
\hline 19 & Lolita & Hembra & 12 años & Criolla \\
\hline 20 & Nieves & Hembra & 7 años & Criolla \\
\hline 21 & Primavera & Hembra & 11 años & Criolla \\
\hline 22 & Chiva & Hembra & 6 años & Bull terrier \\
\hline 23 & Frida & Hembra & 6 años & Labrador \\
\hline
\end{tabular}

Fuente. Elaboración propia.

Los 23 caninos tenían edades en un ran- venes $(20.8 \%)$ y finalmente por los viejos go de 6 meses a 12 años. La mayoría de (12.5\%). Datos que se presentan en la Talas muestras correspondieron a caninos de bla 4 . edad adulta (66.7\%), seguidos por los jó- 
Tabla 4. Frecuencias con relación a la edad de los caninos incluidos en el estudio.

\begin{tabular}{|l|l|l|}
\multicolumn{1}{c|}{ EDAD } & \multicolumn{1}{|c|}{ FRECUENCIA ABSOLUTA } & \multicolumn{1}{c|}{ FRECUENCIA RELATIVA } \\
\hline Joven & 5 & $21.73 \%$ \\
\hline Adulto & 15 & $65.21 \%$ \\
\hline Viejo & 3 & $13.04 \%$ \\
\hline Total & 23 & $100 \%$ \\
\hline
\end{tabular}

Fuente. Elaboración propia.

En cuanto a la característica tamaño de raza, de machos y $45.8 \%$ de hembras, como se se observa predominio del tamańo media- observa en la Tabla 5. no con el 75\%. En cuanto al sexo: 54.2\%

Tabla 5. Frecuencias con relación al tamaño según las razas de los caninos incluidos en el estudio.

\begin{tabular}{|l|l|l|}
\multicolumn{1}{c|}{ TAMAÑO DE RAZA } & \multicolumn{1}{|c|}{ FRECUENCIA ABSOLUTA } & \multicolumn{1}{c|}{ FRECUENCIA RELATIVA } \\
\hline Pequeña & 2 & $8.69 \%$ \\
\hline Mediana & 17 & $73.91 \%$ \\
\hline Grande & 4 & $17.39 \%$ \\
\hline Total & 23 & $100 \%$ \\
\hline
\end{tabular}

Fuente. Elaboración propia.

En cuanto a la recuperación de bacterias ae- nio de Escherichia coli en un $65.21 \%$ de la robias y anaerobias facultativas se encontró población. También se encontró el género que en el $100 \%$ de caninos (23) se iden- Streptococcus en el $17.39 \%$, como se muestificaron bacterias entéricas, con predomi- tra en la Tabla 6.

Tabla 6. Bacterias aerobias y anaerobias facultativas aisladas de la cavidad bucal de los 23 caninos.

\begin{tabular}{|l|l|l|}
\multicolumn{1}{|c|}{ TUBO } & \multicolumn{1}{|c|}{$\begin{array}{c}\text { RESULTADOS } \\
\text { FACULTATIVAS }\end{array}$} \\
\hline 1 & Romana & \multicolumn{1}{c|}{$\begin{array}{c}\text { BACTERICACIÓN CANINO } \\
\text { ADEROBIAS Y ANAEROBIAS }\end{array}$} \\
\hline 2 & Moises & Kluyvera ascorbata, Enterobacter sakazakii, Enterococcus durans \\
\hline 3 & Jein & Enterobacter cloacae, Proteus mirabilis \\
\hline 4 & Chia & Enterococcus hirae \\
\hline 5 & Ice & Streptococcus uberis, Escherichia coli \\
\hline 6 & Mila & Proteus mirabilis, Citrobacter freundii, Escherichia coli \\
\hline 7 & Lucas & Escherichia coli, Enterococcus durans \\
\hline 8 & Mateo & Enterococcus faecalis \\
\hline 9 & Mufasa & Citrobacter freundii \\
\hline 10 & Guache & Kluyvera cryocrencens, Escherichia coli, Streptococcus del grupo \\
\hline
\end{tabular}




\begin{tabular}{|l|l|l|} 
TUBO & \multicolumn{1}{|c|}{ IDENTIFICACIÓN CANINO } & \multicolumn{1}{c}{ RESULTADOS } \\
& \multicolumn{1}{|c|}{ FACULTATIVAS } \\
\hline 11 & Tobi & Escherichia coli \\
\hline 12 & Pecas & Enterobacter cloacae, Proteus mirabilis \\
\hline 13 & Rodrigo & Escherichia coli \\
\hline 14 & Tommy & Proteus mirabilis, Streptococcus del grupo Viridans \\
\hline 15 & Laika & Escherichia coli, Streptococcus del grupo Viridans \\
\hline 16 & Tara & Escherichia coli \\
\hline 17 & Mono & Escherichia coli \\
\hline 18 & Zeus & Escherichia coli \\
\hline 19 & Lolita & Escherichia coli, Enterobacter cloacae \\
\hline 20 & Nieves & Escherichia coli, Enterococcus durans \\
\hline 21 & Primavera & Escherichia coli \\
\hline 22 & Chiva & Escherichia coli \\
\hline 23 & Frida & Kluyvera cryocrencens, Escherichia vulneris, Proteus mirabilis \\
\hline
\end{tabular}

Fuente. Elaboración propia.

De los aislamientos obtenidos, se realizó la las bacterias Gram negativas a partir de agar identificación de bacterias Gram positivas MacConkey, resultados que se muestran en a partir de agar sangre de cordero y para la Tabla 7.

Tabla 7. Características de las unidades formadoras de colonias de las bacterias aerobias aisladas en medios de cultivo.

\begin{tabular}{|c|c|c|}
\hline MEDIO DE CULTIVO & BACTERIAS AISLADAS & $\begin{array}{c}\text { CARACTERISTICAS DE LAS } \\
\text { COLONIAS }\end{array}$ \\
\hline \multirow[t]{6}{*}{ Agar sangre } & & \\
\hline & Enterococcus durans & Pequeñas, blancas, opacas, Beta hemolíticas. \\
\hline & Streptococcus del grupo viridans & $\begin{array}{l}\text { Pequeñas, opacas, blancas, puntiformes. } \\
\text { Gamma hemolíticas. }\end{array}$ \\
\hline & Enterococcus faecalis & $\begin{array}{l}\text { Pequeñas, opacas, blancas. } \\
\text { Gamma hemolíticas. }\end{array}$ \\
\hline & Enterococcus hirae & $\begin{array}{l}\text { Medianas a grandes. } \\
\text { Gamma hemolíticas. }\end{array}$ \\
\hline & Streptococcus uberis & $\begin{array}{l}\text { Colonias pequeñas, redondas, blancas con } \\
\text { gamma hemólisis. }\end{array}$ \\
\hline
\end{tabular}




\begin{tabular}{|c|c|c|}
\hline MEDIO DE CULTIVO & BACTERIAS AISLADAS & $\begin{array}{l}\text { CARACTERÍSTICAS DE LAS } \\
\text { COLONIAS }\end{array}$ \\
\hline & Kluyvera ascorbata & $\begin{array}{l}\text { Medianas, borde redondeados, convexa. } \\
\text { Fermentadora de lactosa. }\end{array}$ \\
\hline & Kluyvera cryocrencens & $\begin{array}{l}\text { Medianas, borde redondeados, convexa. } \\
\text { Fermentadora de lactosa. }\end{array}$ \\
\hline & Enterobacter sakazakii & Grandes, mucoides. Fermentadora de lactosa \\
\hline & Enterobacter cloacae & Medianas, mucoides. Fermentador de lactosa. \\
\hline & Proteus mirabilis & $\begin{array}{l}\text { Incoloras, transparentes. No fermentadora de } \\
\text { lactosa. }\end{array}$ \\
\hline & Escherichia coli & $\begin{array}{l}\text { Medianas, circulares, convexas, bordes } \\
\text { redondeados, rosadas a rojas con halo turbio } \\
\text { (precipitación de bilis). Fermentadora de lactosa. }\end{array}$ \\
\hline & Citrobacter freundii & $\begin{array}{l}\text { Redondas, bordes regulares y seca. } \\
\text { Fermentadora de lactosa. }\end{array}$ \\
\hline & Escherichia vulneris & $\begin{array}{l}\text { Lisas, convexas, medianas y brillantes. } \\
\text { Fermentadoras de lactosa. }\end{array}$ \\
\hline
\end{tabular}

Fuente. Elaboración propia.

En lo relacionado con la identificación de nigrescens reportadas como patógenas cobacterias anaerobias, se encontraron bac- munes en cavidad oral y otras anaerobias terias como Porphyromonas endodontalis, relacionadas con microbiota normal, como Eikenella corrodens, Prevotella intermedial se observa en la Tabla 8.

Tabla 8. Bacterias anaerobias aisladas de la cavidad bucal de los 6 caninos.

\begin{tabular}{|l|l|l|}
\multicolumn{1}{c|}{$\begin{array}{c}\text { TUBO } \\
\text { CANINO }\end{array}$} & \multicolumn{1}{|c|}{ IDENTIFICACIÓN } & \multicolumn{1}{c|}{\begin{tabular}{c}
\multicolumn{1}{c|}{ RESULTADOS } \\
BACTERIAS ANAEROBIAS
\end{tabular}} \\
\hline 4 & Chia & $\begin{array}{l}\text { Fusobacterium spp, Actinomyces spp, Veillonela spp } \\
\text { Prevotella intermedia/nigrescens }\end{array}$ \\
\hline 8 & Mila & Eikenella corrodens \\
\hline 10 & Mateo & $\begin{array}{l}\text { Porphyromonas endodontalis, Actinomyces spp } \\
\text { Fusobacterium spp, Prevotella intermedia/nigrescens } \\
\text { Capnocytophaga spp }\end{array}$ \\
\hline 20 & Pecas & Actinomyces spp \\
\hline 21 & Zeus & \begin{tabular}{l} 
Fusobacterium spp, Actinomyces spp \\
\hline
\end{tabular} \\
\hline
\end{tabular}

Fuente. Elaboración propia. 
Tabla 9. Características macroscópicas de las bacterias anaerobias en medios de cultivo.

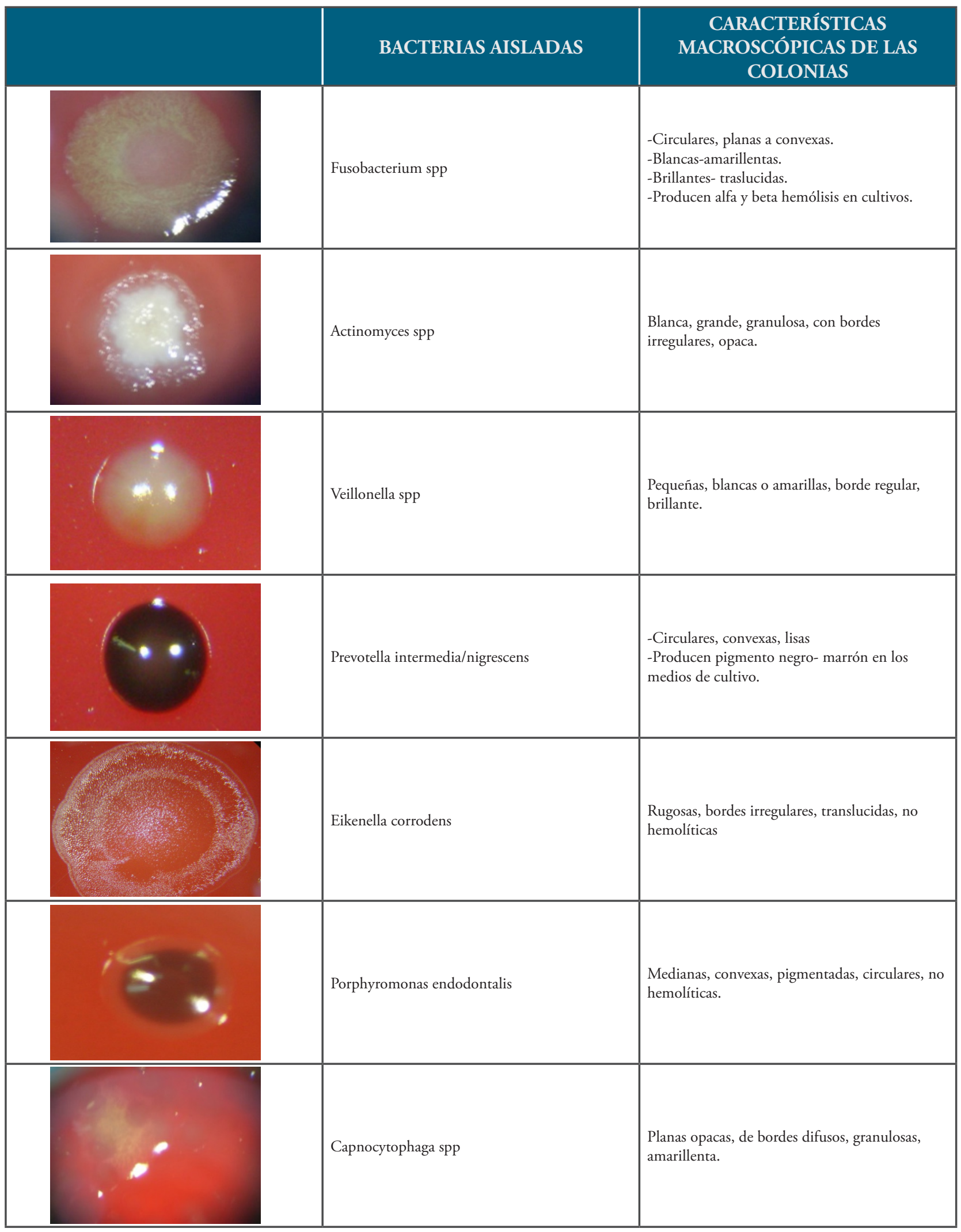

Fuente. Elaboración propia. 
Tabla 10. Distribución y porcentaje de los aislamientos bacterianos en las muestras estudiadas según el análisis morfológico con la coloración de Gram.

\begin{tabular}{|c|c|c|c|}
\hline BACTERIAS & $\begin{array}{l}\text { GRAM POSITIVO } \\
\text { (NÚMERO DE } \\
\text { AISLAMIENTOS) }\end{array}$ & $\begin{array}{l}\text { GRAM NEGATIVO } \\
\text { (NÚMERO DE } \\
\text { AISLAMIENTOS) }\end{array}$ & PORCENTAJE \% \\
\hline Escherichia coli & --- & 15 & $25.4 \%$ \\
\hline Proteus mirabilis & --- & 6 & $10.1 \%$ \\
\hline Actinomyces spp & 5 & --- & $8.4 \%$ \\
\hline Fusobacterium spp & --- & 4 & $6.7 \%$ \\
\hline Prevotella intermedia/nigrescens & --- & 3 & $5 \%$ \\
\hline Enterococcus durans & 3 & --- & $5 \%$ \\
\hline Enterobacter cloacae & --- & 3 & $5 \%$ \\
\hline Streptococcus del grupo Viridans & 3 & ---- & $5 \%$ \\
\hline Capnocytophaga spp & --- & 2 & $3.38 \%$ \\
\hline Citrobacter freundii & --- & 2 & $3.38 \%$ \\
\hline Eikenella corrodens & --- & 2 & $3.38 \%$ \\
\hline Kluyvera cryocrencens & --- & 2 & $3.38 \%$ \\
\hline Porphyromonas endodontalis & --- & 2 & $3.38 \%$ \\
\hline Enterobacter sakazakii & --- & 1 & $1.69 \%$ \\
\hline Kluyvera ascorbata & --- & 1 & $1.69 \%$ \\
\hline Escherichia vulneris & --- & 1 & $1.69 \%$ \\
\hline Veillonela spp & ---- & 1 & $1.69 \%$ \\
\hline Enterococcus hirae & 1 & --- & $1.69 \%$ \\
\hline Streptococcus uberis & 1 & ---- & $1.69 \%$ \\
\hline Enterococcus faecalis & 1 & ---- & $1.69 \%$ \\
\hline Total & 14 & 45 & 100 \\
\hline Frecuencia (\%) & 23.72 & 76.27 & $100 \%$ \\
\hline
\end{tabular}

Fuente. Elaboración propia. 
Figura 3. Distribución de las bacterias aerobias y anaerobias aisladas de la cavidad bucal de los caninos.

\section{Bacterias de la cavidad bucal de los caninos}

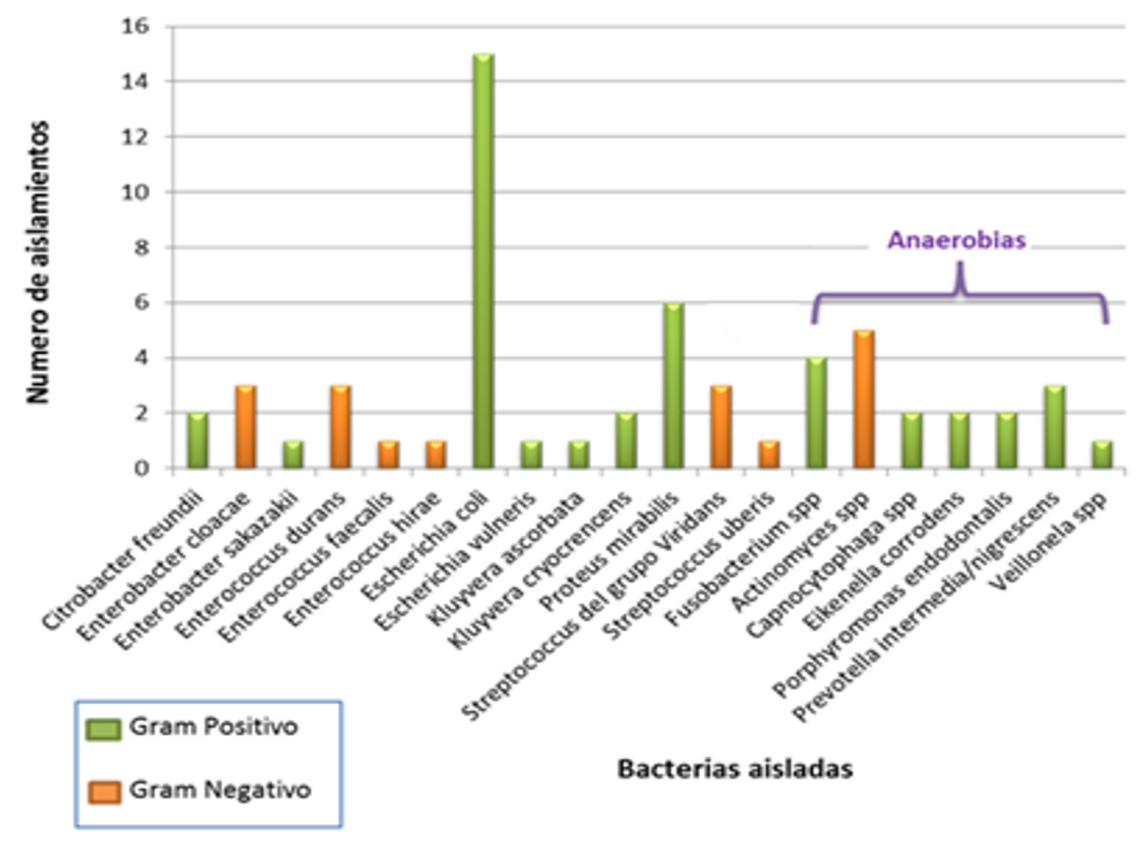

Fuente. Elaboración propia.

Las bacterias aerobias se aislaron en un ma- se encontró en alta proporción en los tres yor porcentaje en la población adulta. De rangos de edad; jóvenes (60\%), adultos estos, como caso particular, Escherichia coli $(62.5 \%)$ y viejos (100\%). Ver Figura 4.

Figura 3. Distribución de las bacterias aerobias y anaerobias aisladas de la cavidad bucal de los caninos.

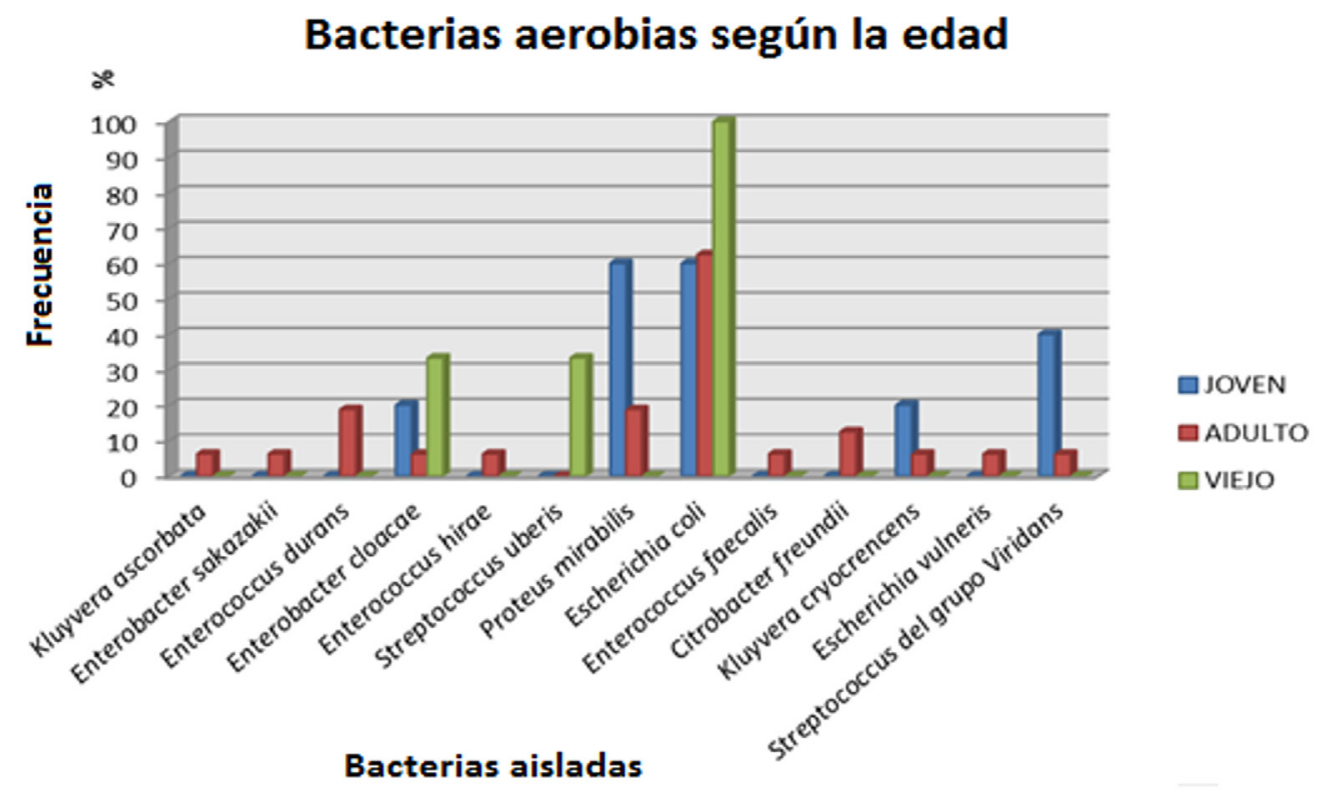

Fuente. Elaboración propia. 
Las bacterias anaerobias aisladas con mayor de edad vieja (muestra 4 y muestra 21) prefrecuencia fueron Actinomyces spp y Fuso- sentando 13000 UFC y 20000 UFC respecbacterium spp, con mayor número de uni- tivamente, como se observa en la tabla 11. dades formadoras de colonia en los caninos

Tabla 11. Recuentos de unidades formadoras de colonias de las bacterias anaerobias estrictas encontradas según edad en los caninos.

\begin{tabular}{|c|c|c|c|c|c|c|}
\hline \multicolumn{7}{|c|}{ CARACTERISTICAS } \\
\hline $\begin{array}{l}N^{\circ} \text { DE MUESTRA DE } \\
\text { CANINO }\end{array}$ & MUESTRA 4 & MUESTRA 8 & MUESTRA 10 & MUESTRA 14 & MUESTRA 20 & MUESTRA 21 \\
\hline SEXO & Hembra & Hembra & Macho & Macho & Macho & Hembra \\
\hline EDAD EN AÑOS & 11 & 7 & 4 & 5 & 7 & 12 \\
\hline GRUPO DE EDAD & VIEJO & ADULTO & ADULTO & ADULTO & ADULTO & VIEJO \\
\hline BACTERIAS ENCONTRADAS & $\mathbf{N}^{\circ}$ UFC & $\mathbf{N}^{\circ}$ UFC & $\mathrm{N}^{\circ}$ UFC & $\mathbf{N}^{\circ}$ UFC & $\mathbf{N}^{\circ}$ UFC & $\mathbf{N}^{\circ}$ UFC \\
\hline Fusobacterium spp & 4000 & ---- & 1000 & --- & 1000 & 2000 \\
\hline Actinomyces spp & 13000 & ---- & 7000 & 8000 & 1000 & 20000 \\
\hline Veillonela spp & 7000 & --.- & --- & --- & --- & --- \\
\hline Prevotella intermedia/ & & & & & & \\
\hline nigrescens & 7000 & --- & 11000 & --- & --- & 8000 \\
\hline Eikenella corrodens & ---- & 1000 & ---- & ---- & ---- & 11000 \\
\hline Porphyromonas endodontalis & ---- & ---- & 6000 & ---- & ---- & 8000 \\
\hline Capnocytophaga spp & ---- & ---- & 1000 & ---- & ---- & 12000 \\
\hline
\end{tabular}

Fuente. Elaboración propia.

Se puede observar que la presencia y proporción de las bacterias anaerobias, en los dos rangos de edad analizados varía; la mayor diversidad de géneros bacterianos se encontró en los caninos viejos (muestras
4 y 21) y un canino adulto (muestra 10). El total de géneros bacterianos de bacterias anaerobias fue 7 , como se observa en la Figura 5. 
Figura 5. Frecuencia de bacterias anaerobias estrictas encontradas según edad.

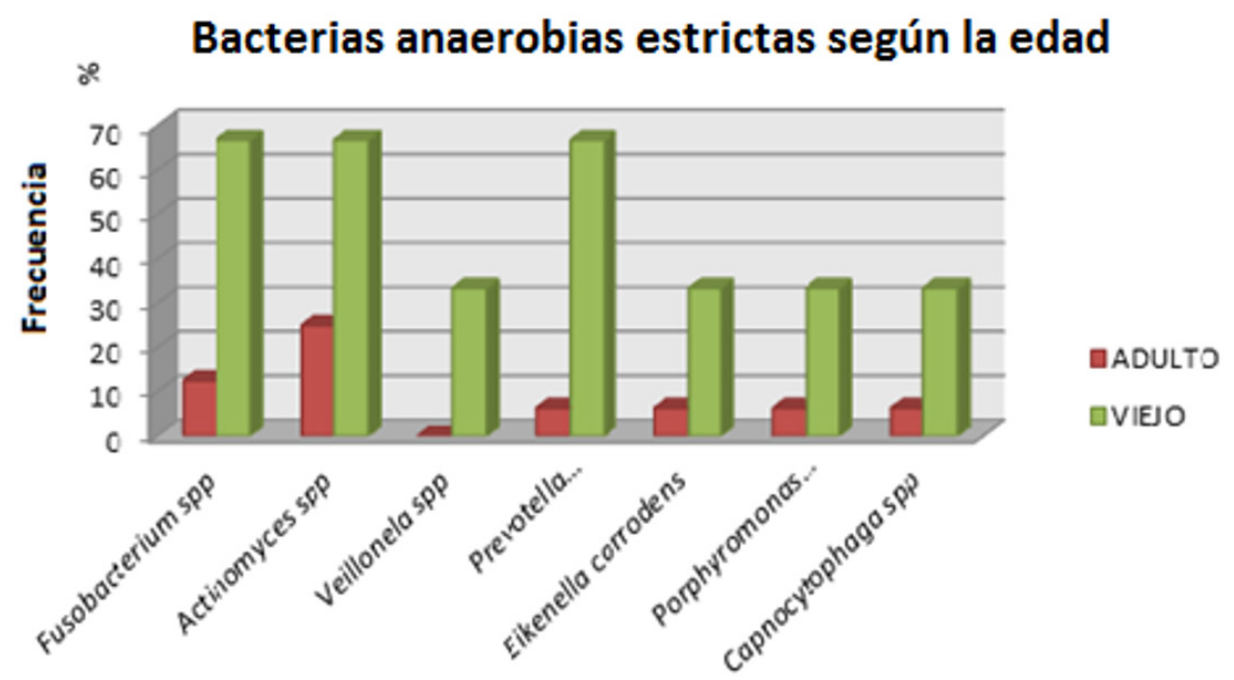

Bacterias aisladas

Fuente. Elaboración propia.

En las bacterias aerobias encontradas, según la bacteria que tuvo mayor frecuencia fue el tamaño del canino, se observó que Esche- Escherichia coli con $70.5 \%$ del total de canirichia coli se identificó en los tres tamaños nos medianos n=17, además de Enterobacy que en cada uno de los tamaños se iden- ter cloacae, Enterococcus hirae y en caninos tificaron diferentes bacterias. En peque- grandes Kluyvera cryocrencen, Escherichia ños: Escherichia coli, Enterococcus durans, coli, Escherichia vulneris, y Enterococcus faeEnterobacter sakazakii, Kluyvera ascorbata y calis. Ver Figura 6.

Streptococcus uberis. En caninos medianos

Figura 6. Frecuencia de bacterias aerobias encontrados según el tamaño.



Fuente. Elaboración propia. 
En la Figura 6 se puede observar que la mayoría de las bacterias identificadas pertenecen a la microbiota intestinal, los cuales se identificaron tanto en tamaño pequeño, mediano y grande de los caninos; particularmente el microrganismo entérico que se aisló en todos los tamaños fue Escherichia coli.

En la identificación de las bacterias anaerobias según el tamaño se puede evidenciar que de los 5 caninos medianos en 4 se encontró Actinomyces spp; en 3 Fusobacterium spp y en 2 Prevotella intermedialnigrescens y Porphyromonas endodontalis. En el tamańo pequeńo la proporción de aislamientos anaerobios fue menor, solo se identificaron en un canino, con un aislamiento por cada microorganismo: Fusobacterium spp, Actinomyces spp, Veillonela spp y Prevotella intermedialnigrescens. Ver Tabla 12 y Figura 7.

Tabla 12. Frecuencias de bacterias anaerobias encontradas en los seis caninos según su tamaño.

\begin{tabular}{|l|l|l|}
\multicolumn{1}{c|}{\begin{tabular}{c}
\multicolumn{2}{c|}{ BACTERIAS } \\
ANAEROBIOS
\end{tabular}} & Pequeño n=1 & Mediano $\mathrm{n}=5$ \\
\hline Fusobacterium spp & 1 & 3 \\
\hline Actinomyces spp & 1 & 4 \\
\hline Veillonela spp & 1 & 0 \\
\hline Prevotella intermedia/nigrescens & 1 & 2 \\
\hline Eikenella corrodens & 0 & 2 \\
\hline Porphyromonas endodontalis & 0 & 2 \\
\hline Capnocytophaga spp & 0 & 2 \\
\hline
\end{tabular}

Fuente. Elaboración propia.

Figura 7. Frecuencia de bacterias anaerobias estrictas encontradas según el tamaño.

\section{Bacterias anaerobias según el tamaño}

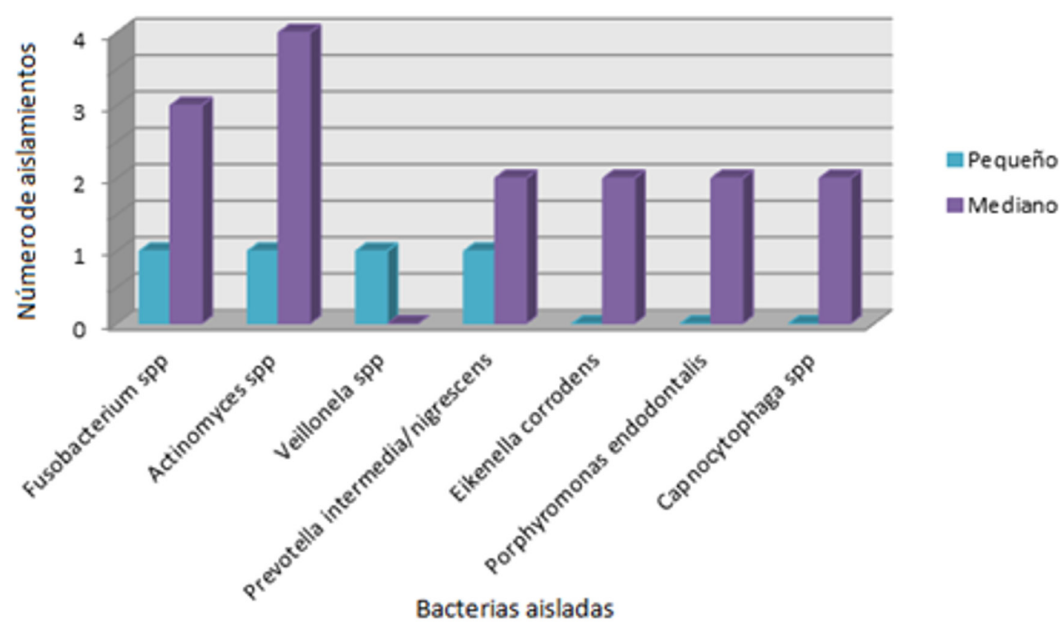

Fuente. Elaboración propia. 
En relación con la identificación de bacterias de acuerdo con el género se encontró que la bacteria aislada con mayor frecuencia tanto en hembras como en machos fue Escherichia coli, con un porcentaje en hembras del $81.81 \%$ del total $\mathrm{n}=11$ y en machos del $58.33 \%$ del total $n=12$. También se observa que en hembras se encontraron ciertas bacterias que no se encontra- ron en los machos como Kluyvera ascorbata, Streptococcus uberis, Enterobacter sakazakii, Escherichia vulneris, Enterococcus durans y Kluyvera cryocrencens. Asímismo, en los machos se encontraron bacterias que en las hembras no, como Enterococcus hirae, Enterococcus faecalis y Citrobacter freundii. Ver Tabla 13 y Figura 8.

Tabla 13. Frecuencias de bacterias aerobias y anaerobias en machos y hembras.

\begin{tabular}{|c|c|c|c|c|}
\hline \multirow[t]{2}{*}{ BACTERIAS } & \multicolumn{2}{|c|}{$\begin{array}{c}\text { HEMBRA } \\
\mathrm{n}=11\end{array}$} & \multicolumn{2}{|c|}{$\begin{array}{c}\text { МACHO } \\
\mathrm{n}=12\end{array}$} \\
\hline & $\mathrm{n}$ & $\%$ & $\mathrm{n}$ & $\%$ \\
\hline Kluyvera ascorbata & 1 & 9.09 & 0 & 0 \\
\hline Kluyvera cryocrencens & 2 & 18.18 & 0 & 0 \\
\hline Enterobacter sakazakii & 1 & 9.09 & 0 & 0 \\
\hline Enterobacter cloacae & 1 & 9.09 & 2 & 16.66 \\
\hline Enterococcus durans & 3 & 27.27 & 0 & 0 \\
\hline Enterococcus hirae & 0 & 0 & 1 & 8.33 \\
\hline Enterococcus faecalis & 0 & 0 & 1 & 8.33 \\
\hline Escherichia coli & 9 & 81.81 & 7 & 58.33 \\
\hline Escherichia vulneris & 1 & 9.09 & 0 & 0 \\
\hline Streptococcus uberis & 1 & 9.09 & 0 & 0 \\
\hline Streptococcus del grupo Viridans & 2 & 18.18 & 1 & 8.33 \\
\hline Proteus mirabilis & 1 & 9.09 & 5 & 41.66 \\
\hline Citrobacter freundii & 0 & 0 & 2 & 16.66 \\
\hline
\end{tabular}

Fuente. Elaboración propia.

Figura 8. Bacterias aerobias y anaerobias presentes en hembras y machos.

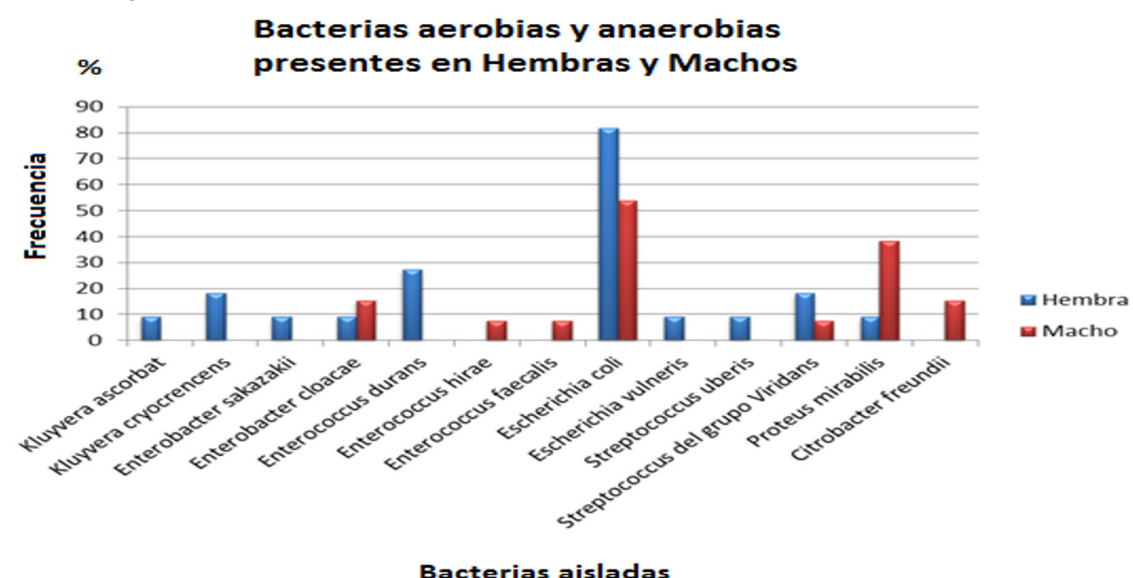

Bacterias aisladas

Fuente. Elaboración propia. 


\section{Discusión}

Los caninos del estudio presentaron diferentes tipos de microorganismos en relación a factores como alimentación, hábitos comportamentales y características propias de cada canino como edad, tamańo y género. Wallis y cols. (19) del Centro Waltham para la nutrición de mascotas en Reino Unido reportan bacterias aerobias $y$ anaerobias facultativas en el estudio que realizaron sobre los cambios en la composición de la comunidad bacteriana asociada al desarrollo de la enfermedad periodontal en caninos. Las bacterias que reportan son: Staphylococcus spp, Micrococcus spp, Bacillus spp, Alcaligenes spp, Pseudomonas spp, Stenotrophomonas $s p p$ y anaerobias estrictas como Peptostreptococcus spp, Bacteroides spp, Fusobacterium spp, Porphyromonas spp y Prevotella spp. Comparando los resultados reportados por Corrin y cols. con los del presente estudio se observan semejanzas en la flora identificada como Streptococcus $s p$, Proteus spp, Escherichia spp, Fusobacterium spp, Porphyromonas spp y Prevotella spp.

En relación con las bacterias entéricas, se observa que el $42 \%$ de la población estudiada, presenta E. coli con un $25.4 \%$. Al respecto Vega y Fernández (20) reportan en su estudio que la presencia de microbiota entérica en caninos con inicios de periodontitis se relaciona con ciertas condiciones del microambiente oral que facilita el crecimiento exacerbado de patógenos oportunistas sobre todo anaerobios, dado que el ambiente facilita su desarrollo. Entre las condiciones se encuentran las higiénico-sanitarias deficientes de los albergues, y la contaminación oro-fecal derivada de hábitos de coprofagia y el lamido frecuente de la zona anal. Además se plantea la importancia de conocer cuál es el tipo de microorganismo que se encuentra en la cavidad bucal, ya que este influye en la terapia antibiótica que se prescriba para tratar las lesiones orales (21).

En relación con Kluyvera spp se describe con poca frecuencia en asociación con infecciones clínicamente significativas en humanos. Kluyvera ascorbata y Kluyvera cryocrecens identificadas en el presente estudio no se reportan en la literatura consultada con microbiota bucal en caninos o infecciones orales en los mismos, aunque se ha descrito que es una bacteria oportunista y patógena y se encuentra en diferentes ambientes (22).

Porphyromonas spp. se ha reportado en enfermedad periodontal y su crecimiento es estimulado por la placa dentobacteriana, en la cual coexiste con otros microorganismos que consumen el oxígeno del medio y generan el potencial redox adecuado para su proliferación, tal como lo reportan Vega y Fernández (20), en su estudio realizado en 30 caninos de diferentes albergues. El género Actinomyces se reporta en enfermedad periodontal y fue aislado en el $8.4 \%$ de las muestras. Al respecto Takada y Hirasawa, (23) sugieren que esta bacteria puede desempeñar el mismo papel en la periodontitis canina que Porphyromonas gingivalis en la periodontitis del humano. Otras bacterias 
encontradas que comparten los dos estudios fueron Fusobacterium, Prevotella, y Streptococcus spp.

Los géneros bacterianos aislados de las cavidades orales de los perros, son similares a las que se encuentran en la placa dental humana. En un estudio similar Gavin y cols. (24) identificaron Fusobacterium spp, el cual es un microorganismo capaz de adherirse y formar biofilms. Se reporta en la cavidad oral de humanos y fue encontrado en algunos caninos del estudio. Sin embargo, otros patógenos periodontales del humano, como Porphyromonas gingivalis y Tannerella forsythensis, no fueron encontrados en ninguna de las muestras analizadas.

En relación con la edad, se observa que el género Enterococcus spp., se encuentra en caninos adultos; al respecto Semedo y cols. (25), encontraron en 32 caninos con edades de los 7 a los 16 años E. faecalis y E. faecium.

En el caso de los microorganismos encontrados de acuerdo con el tamaño de los caninos; se obtuvo que en los medianos hay mayor prevalencia de enterobacterias, entre las cuales está Proteus mirabilis. A propósito de esta característica, Cabrera y cols. (11), en un estudio realizado en Beagles, considerados una población de tamaño mediano, encontraron Proteus mirabilis, pero además Staphylococcus aureus y Neisserias spp., las cuales no fueron encontradas en ninguno de los caninos de raza Beagle del presente estudio.
En relación con la microbiota encontrada según el género se encontró en las hembras bacterias como Kluyvera ascorbata, Streptococcus uberis, Enterobacter sakazakii, Escherichia vulneris, Enterococcus durans y Kluyvera cryocrencens las cuales no se encontraron en los machos. Así mismo, en los machos se encontraron bacterias que en las hembra no, como Enterococcus hirae, Enterococcus faecalis y Citrobacter freundii. En relación con la microbiota oral y el género en caninos no se encontró información en la literatura indagada. Sin embargo, Rotemberg y Smaisik (26) plantean que en el humano la presencia de bacterias en enfermedad periodontal es influyente y está relacionada con los cambios hormonales en la mujer más que en el hombre. Jofré y cols. (27), de la Sociedad Chilena de Infectología, describen que la mayoría de las infecciones producidas por mordedura como celulitis, artritis séptica, osteomielitis, septicemia, meningitis y endocarditis, tienen una etiología polimicrobiana encontrando agentes aerobios como Pasteurella multocida y Staphylococcus aureus, Streptococcus spp, Moraxella spp, Neisseria $s p$, Corynebacterium spp, Eikenella corrodens, Capnocytophaga canimorsus, entre los agentes anaerobios estrictos se encuentran Bacteroides fragilis, Fusobacterium spp y Veillonella párvula. Por lo tanto, se encuentra similitud entre las bacterias descritas y las halladas en el presente estudio. En este sentido, las mordeduras pueden causar grandes infecciones, de tal forma que es importante conocer la caracterización de la microbiota bucal de los caninos, para así 
lograr un manejo y tratamiento adecuado de las infecciones (15).

La microbiota bucal está estrechamente relacionada con procesos infecciosos y enfermedades orales, ha sido estudiada e investigada de manera experimental en caninos en diferentes países, pero no en Colombia, razón por la cual, es importante realizar estudios que permitan conocer qué bacterias hacen parte de ese ecosistema en los caninos de nuestro medio, ya que las condiciones específicas de cada animal y sus hábitos influyen en la conformación de esta microbiota, así como en la aparición de infección o enfermedad oral, condiciones que no necesariamente son las mismas que se encuentran en otros países.

Conocer los microorganismos implicados en lesiones orales, así como los que se pueden trasmitir al humano por el contacto físico cercano o a través de las mordeduras, contribuye a un mejor diagnóstico y orienta el tratamiento tanto en la infección en el animal como en el humano, y por ende, aporta a la salud pública $(16,20)$.

\section{Conclusiones}

La microbiota oral encontrada en los caninos en condición de abandono de la Fundación Razas Únicas, del municipio Chía (Cundinamarca - Colombia), evidencia que ésta se encuentra estrechamente relacionada con el estilo de vida de los caninos y que de acuerdo a sus hábitos, factores ambientales y comportamentales se pueden aislar diversas bacterias como parte de la microbiota natural oral y/o como causantes de lesiones orales e infecciones oportunistas.

Según la literatura y los resultados obtenidos en el presente estudio, se demuestra que las bacterias patógenas implicadas en lesiones periodontales en los caninos son bacterias anaerobias como Eikenella corrodens, Porphyromonas endodontalis y Fusobacterium spp. Además, se han encontrado estudios donde reportan bacterias no implicadas directamente en la infección periodontal pero que pueden participar en la generación de un ambiente propicio para su desarrollo, de tal forma que facilitan el crecimiento exacerbado de patógenos oportunistas sobre todo anaerobios facultativos entéricos: Escherichia coli, Proteus mirabilis, Citrobacter freundii, Enterobacter sakazakii, Enterobacter cloacae, bacterias Gram positivas como Enterococcus durans y, Enterococcus faecalis, asociadas a la flora intestinal del animal como consecuencia de sus condiciones higiénico-sanitarias y hábitos que conllevan a contaminación oro-fecal.

El estudio realizado evidenció la presencia de microorganismos en la flora bucal de hembras que no se encuentran en los machos y viceversa, y se constituye en el primer reporte referente a la flora presente en cavidad oral en caninos con relación al género. Las bacterias halladas se encuentran asociadas a infecciones en la cavidad bucal, en donde se resalta la presencia de Kluyvera ascorbata, Streptococcus uberis, Enterobacter 
sakazakii, Escherichia vulneris, Enterococcus durans y Kluyvera cryocrencens sólo en hembras y Enterococcus hirae, Enterococcus faecalis, Citrobacter freundii únicamente en machos.

La transmisión de bacterias patógenas de la boca por mordeduras de caninos a los humanos es una situación de salud pública, sobre la cual existen pocos estudios en Colombia. La identificación de los microorganismos en las lesiones por mordeduras o en la cavidad bucal de caninos permite orientar el tratamiento antimicrobiano específico tanto para el humano como para el animal y evitar el desarrollo de enfermedades secundarias.

La presencia de microorganismos en la cavidad bucal de los caninos está influenciada por el medio ambiente que lo rodea y los hábitos y costumbres del animal. Los microorganismos pueden transmitirse entre caninos por la convivencia, así como a los humanos donde se pueden convertir en verdaderos agentes infecciosos, principalmente a personas con un sistema inmune susceptible como el de los niños y personas de la tercera edad.

\section{Agradecimientos}

A la Dra. Diana Marcela Castillo, Instituto UIBO, Universidad El Bosque.

A la Fundación Razas Únicas, por la labor tan especial que hacen con los animales.

\section{Referencias}

1. Dewhirst FE, Klein EA, Thompason EC, Blanton JM, Chen T, Milella L, Buckley CMF, Davis IJ, Bennett M-L, Marshall-Jones ZV. The canine oral microbiome. PLoS One [Internet]. 2012 [citado 20 junio 2018]. 7:e36067. Disponible en: http://journals.plos.org/plosone/article?id=10.1371/journal. pone. $0036067 \#$ s2

2. Holcombe L, Patel N, Colyer A., Deusch O, O'Flynn C, Harris S. Early Canine Plaque Biofilms: Characterization of Key Bacterial Interactions Involved in Initial Colonization of Enamel. PLoS One. [Internet]. 2014[citado 30 octubre 2018]; 9(12): e113744. Disponible en: http://www.ncbi.nlm.nih. gov/pmc/articles/PMC4252054

3. Corredor C., Torres A. Microbiología de las lesiones pulpares. [Tesis]. Bogotá Colombia: Pontificia Universidad Javeriana. Facultad de Ciencias. Febrero 2009. [citado 5 octubre 2018]. Disponible en: http://www.javeriana.edu.co/biblos/tesis/ciencias/ tesis229.pdf

4. Serrano H, Sanchez M, Cardona N. Conocimiento de la microbiota de la cavidad oral a través de la metagenómica Revista CES Odontología [Internet]. 2015 [citado 15 agosto 2018]; 28(2). Disponible en: http://www.scielo.org.co/pdf/ceso/v28n2/ v28n2a09.pdf

5. Martínez M.A. Microorganismos asociados a infecciones por mordeduras de perros y gatos. Facultad de Medicina, Universidad de Chile. Mon. Electr. Patol. Vet. [Internet]. 2005. [actualizado 12 Abril 2005; 30 Mayo 2018]; 2(1). Disponible en: http:// www.patologiaveterinaria.cl/Monografias/MEPAVET1-2005/PDF/MEPAVET07.pdf

6. Negro V.B., Hernández S.Z, Pereyra A, Rodríguez D.I., Ciappesoni J.L., Saccomanno D.M. et al. Bacterias subgingivales aisladas de perros con enfermedad periodontal y su susceptibilidad a antimicrobianos. Primera comunicación en la República Argentina. InVet [Internet]. 2012 Dic [citado 
30 agosto 2018]; 14(2):141-149. Disponible en: http://www.scielo.org.ar/scielo.php?script=sci_arttext $\&$ pid $=$ S1668-34982012000200002\&lng=es.

7. Albuquerque C, Morinha F, Requicha J, et al. Canine periodontitis: The dog as an important model for periodontal studies. The Veterinary Journal [Internet]. 2012 [citado 5 septiembre 2018]; 191(3) Disponible en: http://www.ncbi.nlm.nih.gov/pub$\mathrm{med} / 21940182$

8. Toledo M.F. Estudio descriptivo de patologías y lesiones orales en pacientes caninos domésticos. [Tesis]. Santiago, Chile: Universidad de Chile. Facultad de ciencias veterinarias y pecuarias escuela de ciencias veterinarias; 2004. [citado 5 septiembre 2018]. Disponible en: http://repositorio.uchile.cl/ bitstream/handle/2250/130879/Estudio-descriptivo-de-patolog\%C3\%ADas-y-lesiones-orales-en-pacientes-caninos-dom\%C3\%A9sticos.pdf?sequence $=1$ \&isAllowed $=y$

9. Mally M, Paroz C, Shin H, Meyer S, Soussoula LV , Schmiediger T et al. Prevalence of Capnocytophaga canimorsus in dogs and occurrence of potential virulence factors. Microbes Infect. [Internet]. 2009 [citado 12 agosto 2018]; 11(4):509-14. Disponible en: http://www.ncbi.nlm.nih.gov/pub$\mathrm{med} / 19285152$

10. Santin R, Mattei AS, Waller SB, Stefanie BW, Isabel MM, Marlete BC et al. Clinical and mycological analysis of dog's oral cavity. Brazilian Journal of Microbiology. [Internet]. 2013 [citado 30 octubre 2018]; 44(1):139-143. Disponible en: http://www. ncbi.nlm.nih.gov/pmc/articles/PMC3804190/

11. Cabrera G. A, Guerra B.M, Soca P. M, Víctor M. D, Heberto Arides, Luis S. C. Flora bucal en perros de la raza Beagle con enfermedad periodontal inducida. REDVET. [Internet]. 2012 [citado 15 agosto 2018]; 13(1). Disponible en: http://www.veterinaria.org/revistas/redvet/n010112/011209.pdf

12. Peña M, Calzado M, Peña M, Cordero S, Azahares H. Patógenos periodontales y sus relaciones con enfermedades sistémicas. MEDISAN [Internet]. 2012 [citado 30 octubre 2018]; 16(7):1047 Disponible en: http://bvs.sld.cu/revistas/san/vol_16_7_12/ san 14712.pdf

13. Torres M. Relación huésped parasito: flora humana normal. Instituto de Higiene. [Internet]. Uruguay 2002 [actualizado 2 Junio 2015; citado 4 Oct 2018]; Disponible en: http://www.higiene.edu.uy/ cefa/Libro2002/Cap\%2013.pdf

14. Clínica de Cirugía Bucal, Maxilofacial e Implantes. [Internet]. San Salvador Lucas M. Artículo de publicación: Infecciones Odontogènicas [actualizado 2 Junio 2015; citado 4 septiembre 2018]; Disponible en: http://www.doctorlucasmiralda.com/infecciones_odontogenicas_doctor_miralda.pdf

15. Muñoz L.F. Mordedura canina. Artículo de revisión. Univ. Méd. [Internet]. Bogotá (Colombia), enero-marzo, 2012 [citado 15 septiembre 2018]; 53 (1): 43-55, Disponible en:http://med.javeriana.edu. $\mathrm{co/publi/vniversitas/serial/v53n} 1 /$ Mordedura\%20 Canina.pdf

16. Oh C, Lee K, Cheong Y, Lee S-W, Park S-Y, Song $\mathrm{C}-\mathrm{S}$, et al. Comparison of the Oral Microbiomes of Canines and Their Owners Using Next-Generation Sequencing. PLoS ONE [Internet]. 2015 [citado 15 septiembre 2018]. 10(7): e0131468. Disponible en: http://journals.plos.org/plosone/article?id=10.1371/journal.pone. 0131468

17. Díaz J, Yáñez J, Melgar S, Álvarez C, Rojas C, Vernal R. Virulencia y variabilidad de Porphyromonas gingivalis y Aggregatibacter actinomycetemcomitans y su asociación a la periodontitis. Rev. Clin. Periodoncia Implantol. Rehabil. Oral [Internet]. 2012. [citado 30 septiembre 2018]. Vol. 5(1); 40-5 Disponible en: http://www.scielo.cl/scielo.php?scrip$\mathrm{t}=$ sci_arttext\&pid=S0719-01072012000100007

18. Logan EI, RB Wiggins, K Zetner, JJ Hefferren. 2000. Enfermedad dental. En: Hand MS, Thatcher CD, Remillard RL, Roudebush P. Nutrición clínica en pequeños animales. 4a Ed. Pp. 561- 584. Mark Morris Institute. Santa Fe de Bogotá, Colombia. 
19. Wallis C, Marshall M, Colyer Al, O'Flynn C, Deusch $\mathrm{O}$, Harris S. A longitudinal assessment of changes in bacterial community composition associated with the development of periodontal disease in dogs. Elsevier- Veterinary Microbiology. [Internet]. 2015. [citado 30 septiembre 2018] 181(3-4) Disponible en: http://ac.els-cdn.com/S0378113515300213/1s2.0-S0378113515300213-main.pdf?_ti$\mathrm{d}=\mathrm{aea} 7 \mathrm{a} 4 \mathrm{ee}-53 \mathrm{a} 3-11 \mathrm{e} 6-\mathrm{aa} 77-00000 \mathrm{aacb} 362 \& \mathrm{acd}-$ nat $=1469587495 \_028$ b6aa29f4b51c300003eeeefofd 4

20. Vega H, Fernández V, Morales S, Calle S, Pérez C. Determinación de la susceptibilidad antibiótica in vitro de bacterias subgingivales en caninos con enfermedad periodontal moderada a severa. Revista de Investigaciones Veterinarias del Perú. [Internet]. Lima 2014. [Citado 30 septiembre 2018]; 25(1) Disponible en: http://www.scielo.org.pe/scielo.php?pid=S1609-91172014000100009\&script=sci_arttext

21. San Román F. Enfermedad periodontal en perros y humanos. Odontología Veterinaria - Aspectos recientes sobre su manejo clínico y económico en la práctica veterinaria Madrid, Espańa 7 de Marzo de 2013. [Citado 30 septiembre 2018]; Disponible en: http://www.clinicalvetnews-eukanuba.com/uk/ pdf/Proceedings_201303_SP.pdf

22. Sarria J, Vidal A and Kimbrough R. Infections Caused by Kluyvera Species in Humans. Clin Infect Dis. [Internet]. 2001 [Citado 27 octubre 2018]; 33 (7) Disponible en: http://cid.oxfordjournals.org/ content/33/7/e69.full

23. Takada, K., and M. Hirasawa. Expression of trypsin-like activity by the genera Corynebacterium and Actinomyces in canine periodontitis. J. Med. Microbiol. [Internet]. 2000. [Citado 25 octubre 2018]; 49:621-625

24. Gavin G, Victoria S. L, Graham R, Aviva P, Wilson M and Spratt D. 2004. Prevalence of periodontal pathogens in dental plaque of children. J. Clin. Microbiol. [Internet]. 42:4141-4146.Dispo- nible en: http://jcm.asm.org/content/42/9/4141. abstract?ijkey=30a22ee8ed8840e74c7b85ee9d4bb340b00a8ce8\&keytype2=tf_ipsecsha

25. Semedo T, Tavares M, São B, Tavares L, and Oliveira M. Enterococcal Infective Endocarditis following Periodontal Disease in Dogs PLoS One. [Internet]. 2016; [Citado 24 octubre 2018]; 11(1): e0146860. Disponible en: http://www.ncbi.nlm.nih.gov/pmc/ articles/PMC4709084/

26. Rotemberg E., Smaisik K., Manifestaciones periodontales de los estados fisiológicos de la mujer. Odontoestomatología [Internet]. 2009. [citado 24 Agosto 2018]; 11 (13) Disponible en: http://www.scielo.edu.uy/scielo.php?pi$\mathrm{d}=$ S1688-93392009000200003\&script=sci_arttext

27. Jofré L, Perret C, Abarca k, Solari V, Olivares R. y López J. Recomendaciones para el manejo de mordeduras ocasionadas por animales. Rev Chil Infect [Internet]. 2006; [Citado 13 octubre 2018]; 23 (1): 20-34 Disponible en: http:// www.scielo.cl/scielo.php?script $=$ sci_arttext $\&$ pi$\mathrm{d}=$ S0716-10182006000100002 